\title{
PRESENTACIÓN
}

\section{Un modelo mexicano de enseñanza del trabajo de campo}

\author{
Marisol Pérez Lizaur
}

$\mathrm{L}$ os artículos que conforman la sección "Saberes y razones" de este número de la revista mesa "Fieldwork Training in the Field: The Global Legacies of a Mexican Model" - "La enseñanza del trabajo de campo: los legados globales de un modelo mexicano"- en la Reunión 110 de la American Anthropological Association (AAA) el 19 de noviembre de 2011, en Montreal, Canadá. En 2010, en la Reunión 109 de la AAA en Nueva Orleans, Frances Rothstein me invitó a presentar una ponencia sobre el curso de antropología mexicana que imparto en la Universidad Iberoamericana (UIA) en una sesión de la Comisión de Antropologías del Mundo. Se presentaron varias ponencias sobre las formas de enseñar la antropología en distintas partes del mundo, mas la sesión no despertó el interés de los estadounidenses. Esta circunstancia nos motivó a discutir a Frances Rothstein, Gustavo Lins Ribeiro y a mí sobre el escaso interés de los antropólogos estadounidenses en los aportes de las antropologías de otros países.
Con esta preocupación en la cabeza leí la convocatoria para el siguiente congreso en Montreal. El tema sería "Traces, Tidemarks and Legacies" - "Huellas, corrientes y legados" - y me recordó la conversación con Rothstein y Lins Ribeiro sobre la importancia de estos temas a nivel internacional en el desarrollo de la ciencia, incluida la antropología (Barnes y Edge, 1982). Pensé que la presentación de una mesa en la que destacáramos las huellas, las corrientes y los legados de la antropología mexicana podría despertar el interés de los antropólogos estadounidenses en ella. Comenté esta idea con Roger Magazine, formado en los Estados Unidos, y le pareció interesante, siempre y cuando nos centráramos en destacar un aporte específico de la antropología mexicana a la disciplina a nivel internacional. A partir de esta conversación, Magazine sugirió que una contribución significativa es la metodología de la enseñanza del trabajo de campo en la UIA. Con base en ese intercambio de ideas, decidimos armar una mesa en la que las ponencias ponderaran no sólo los orígenes, las características y el desarrollo de esta

\section{A Mexican Model of Fieldwork Teaching}

Marisol Pérez Lizaur: Universidad Iberoamericana, Distrito Federal, México marisol_perez@prodigy.net.mx

Desacatos, núm. 45, mayo-agosto 2014, pp. 7-9 
metodología, sino también su influencia en otras latitudes. Una decisión fundamental fue solicitar asesoría para la mesa a la Comisión de Antropologías del Mundo, en particular a Gustavo Lins Ribeiro, quien entendió y apoyó nuestra propuesta con gran generosidad.

Desde un inicio consideramos que las ponencias tendrían que tratar sobre los orígenes de la metodología de la enseñanza del trabajo de campo, sus influencias y huellas en el desarrollo de la antropología. Esto implicaba dar razón de cómo se ha enriquecido y adaptado la metodología a las condiciones del entorno, así como a los requerimientos, el carácter y los recursos de las instituciones, los maestros y los estudiantes. Así que decidimos que yo hablaría del origen de la metodología en la Universidad Iberoamericana y Roger Magazine de la manera en que se lleva a cabo hoy en día. Para mostrar sus influencias globales decidimos invitar a exponer sus experiencias en Estados Unidos a Laura González y a Víctor García, de la Indiana University of Pennsylvania, y en España sobre la propiedad de los datos obtenidos a través del trabajo de investigación en grupo.

En "Beneficios y retos de la enseñanza del trabajo de campo en el campo: el caso del posgrado en antropología social de la Universidad Iberoamericana, ciudad de México", Roger Magazine relata cómo se llevan a cabo hoy las prácticas de campo en el programa de posgrado en antropología de la UiA. Además de describir con detalle la metodología y las relaciones con los estudiantes, analiza la incidencia de la cultura y de las políticas nacionales de ciencia y tecnología en la metodología de la enseñanza de la investigación y conmina a proseguir con la discusión alrededor de la propiedad de los datos de campo. En "Expandiendo la tradición de Ángel Palerm: estaciones de campo, etnografía, reclutamiento y retención de estudiantes latinos", Laura González y Víctor García dan testimonio de la labor de Juan Vicente Palerm, hijo de Ángel, en la enseñanza en México y en los Estados Unidos de la metodología del trabajo de campo diseñada por su padre. En el relato sobresale el papel de las casas de campo en la formación y retención de estudiantes latinos en los Estados Unidos. Esta discusión invita a reflexionar y a profundizar sobre lo sugerido por Roger Magazine en su artículo acerca de las diversas concepciones sobre el individuo y el grupo en ambas culturas, así como en su incidencia en la enseñanza y en la investigación.

Por su parte, Carlos Giménez Romero, en "La articulación de teoría, trabajo de campo y formación del antropólogo en Ángel Palerm. Transfiriendo aprendizajes de México a España”, se aproxima a la transmisión de la metodología de la enseñanza del trabajo de campo al estilo de Palerm desde la UIA hasta España, pasando por la experiencia del aprendizaje en la Universidad Autónoma MetropolitanaIztapalapa y en California. Esta colaboración es particularmente interesante porque se refiere al papel de los estudiantes de Palerm, en especial el de su hijo Juan Vicente, en la transmisión de esta metodología a nuevos estudiantes y en la formación de investigadores que hoy forman a otros más en 
España. También resalta la relevancia del entorno institucional en la posibilidad real de reproducir este modelo. Para finalizar, la sección "Saberes y razones" de este número de la revista Desacatos incluye los comentarios de Robert V. Kemper y Gustavo Lins Ribeiro, quienes comparan los trabajos citados desde las perspectivas estadounidense y brasileña, y reflexionan así sobre la importancia de la acción de líderes académicos en el desarrollo de la disciplina.

\section{BIBLIOGRAFÍA}

Barnes, Barry y David Edge (eds.), 1982, Science in Context: Readings in the Sociology of Science, Open University Press, MIT Press, Londres y Cambridge. 